\title{
La deriva poética del relato audiovisual
}

\section{The poetic drift of the audiovisual story}

\author{
Ana González Wonham ${ }^{1, *}$ \\ ${ }^{1}$ Facultad de CCII, Universidad Complutense de Madrid \\ * Correspondencia:
}

Received: 12/03/2020; Accepted: 01/05/2020; Published: 03/07/2020

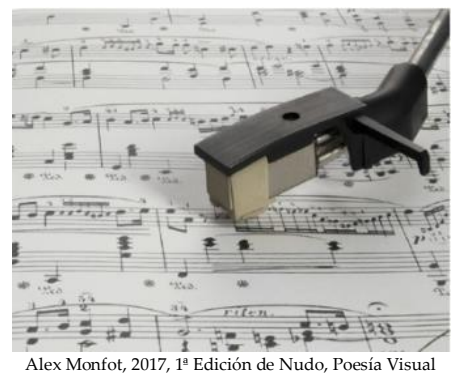

\section{Resumen:}

El presente artículo analiza la deriva poética en los nuevos códigos narrativos de formatos audiovisuales, en concreto de los relatos de ficción fílmica y televisiva, para establecer si estos nuevos modos de construcción de la ficción cuestionan o refrendan las sustancias expresivas del discurso poético. La metodología, eminentemente cualitativa, incluyó el estudio de cuatro ejemplos de caso, dos series de ficción de televisión emitidas en plataformas digitales y canales de televisión convencionales y dos películas de distribución cinematográfica. En todos los casos se identificaron indicadores de análisis del reflejo de una realidad con valores inherentes a la escritura poética: intensidad, candor, nobleza y heroísmo, por un lado, y urgencia y necesidad vitales como estímulos creativos. La poesía está inherente en los relatos audiovisuales como una inyección de afectividad que dinamita la acción. El discurso poético metaforiza, sintetiza y nombra, y nuestras ficciones audiovisuales son deudores de este pulso creativo.

Palabras Claves: Deriva poética, relato audiovisual, intensidad, afectividad, metáfora.

\begin{abstract}
:
This article analyses the poetic drift of the new narrative codes in audiovisual phormats, specially in cinema and televisión fiction, to stablish if these new ways of fiction writing support or deny the expressive substances of the Poetry speech. The methodology, eminently qualitative, included the examination of four samples, two television fiction series broacasted in digital platformas and conventional TV channels, and two films distributed by the film industry. All of them registered indicators of analysis in which reality was built with poetic figures: intensity, sincerity, nobility and heroism, on the one hand, and daily needs and urge as a creative encouragement. Poetry is attached to audiovisual stories as an emotion injection which blows the action up. The poetic speech gives metaphors, encapsulates and appoints, our audiovisual fictions are in debt with this creative challenge.
\end{abstract}

Keywords: Poetic drift/ Audiovisuals/Intensity/Emotion/Metaphor

\section{Introducción}

En escritura poética, narratividad y análisis de la creatividad, todos somos herederos de Aristóteles, sobre todo de una de sus obras mayores, "La Poética". Si queremos analizar los mecanismos de una "deriva poética" en los nuevos códigos narrativos audiovisuales debemos acudir a la filosofía. Según el genial pensador griego, "la Poética es el arte de componer poemas principalmente trágicos (...) La poesía no es elocuencia, produce la purificación de las pasiones del 
temor y la compasión". Estamos, pues, a las puertas de una sublimación, de un esfuerzo en la definición del propio acto poético, que se nutre de la realidad pero que la cubre de un manto de verdad y belleza.

Pero, entonces, ¿qué es la poesía? Difícil nombrar a una actividad creadora que nombra, sustantiviza, señala y elige. Desde la cátedra de Comunicación Audiovisual de la Facultad de Ciencias de la Información, Universidad Complutense de Madrid, nos llega esta definición posible:

¿Qué es la poesía? Lo que está por descubrir, todo luz sin costuras ni límites, una luz absoluta sin espacio, ni tiempo, con ausencia de esquinas, con plenitud presente de las horas(...) un saber más de todo lo existente que trasciende toda razón y ciencia.

GARCÍA GARCÍA, FRANCISCO, (2019) Presentación poemario "Rimas y Venenos", Icono 14, Madrid.

La voz poética imanta un saber trascendente, una corporeidad sin límites, presencias y ausencias plenas en un contexto de espacio/tiempo que se transgrede. La construcción poética arrasa cuando contradice, reclama y establece juegos de antagonismos.

\author{
"No me gusta \\ cómo la vida nos entrelazó: \\ en nudos: \\ sin brisas, \\ en monólogos: \\ sin palabras, \\ en cartas: \\ sin correspondencias,
}

en amor:

sin existencia"

LEVESQUE, SARA, (2018) Poema al olvido, web Bohemia te adoro, Madrid.

¿Y este discurso poético nos sirve para desarrollar la creatividad, la comunicación, para la construcción de relatos? Discurso inconsciente o cerebral, nos cuenta un poeta:

Los tres mejores ejercicios, los únicos quizás para la inteligencia, son hacer versos, cultivar las matemáticas y dibujar (...) Son ejercicios por excelencia, actos no necesarios, sometidos a condiciones impuestas, arbitrarias y rigurosas.

VALÉRY, PAUL, (2007) Cuadernos (1894-1945), Galaxia Gutemberg, Barcelona.

La actividad poética mejora la dicción y la expresión oral, favorece la empatía, el desarrollo emocional y cognitivo, estimula la imaginación y la memoria. Provoca el diálogo, también el desconcierto, es un encuentro de estrategias y seducciones.

"Mi táctica es

hablarte y escucharte 


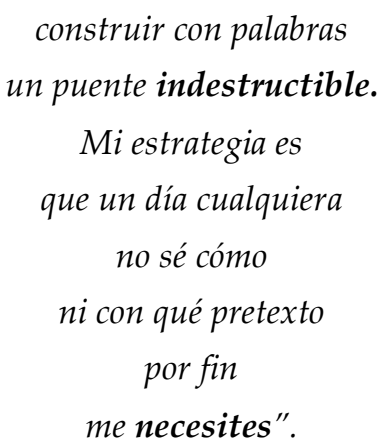

BENEDETTI, MARIO (1984)_ “Táctica y estrategia”, Poemas de otros, Visor, Madrid. Esa "necesidad táctica" del discurso poético entronca con la teoría del énfasis de Susan Sontag que, a golpe de bisturí, descifró las sustancias expresivas del lenguaje poético:

La poesía es una forma del lenguaje y del ser: un ideal de intensidad, candor absoluto, nobleza y heroísmo.

SONTAG, SUSAN (1983) La prosa de un poeta. Cuestión de énfasis. Alfaguara, Madrid.

La poesía tiene un fin celebratorio, de disfrute comunitario, aunque proceda de la urgencia y la necesidad individual. En los recitales poéticos su puesta en escena tiene una vocación humana y social muy próxima a la ficción audiovisual tanto en cine como en televisión, también lo habita el teatro. Lejos de la inutilidad percibida por algunos, sirve, en palabras del poeta Alejandro Simón, "para no caer en esta época de cinismo, odio y escepticismo que vivimos". Corroboramos a Pablo Neruda en la defensa de su oficio: "El poeta amasa el pan difícil pero honrado de la vida". Ese "amasar" de la vida traducido en versos de ausencias y reclamos. En un nuevo duelo y pulsión narrativos, el discurso poético habita la soledad de la escritura y, al tiempo, añora las alas para alcanzar la libertad creativa, ansía volar hacia ese "nunca" que es un "siempre" disfrazado.

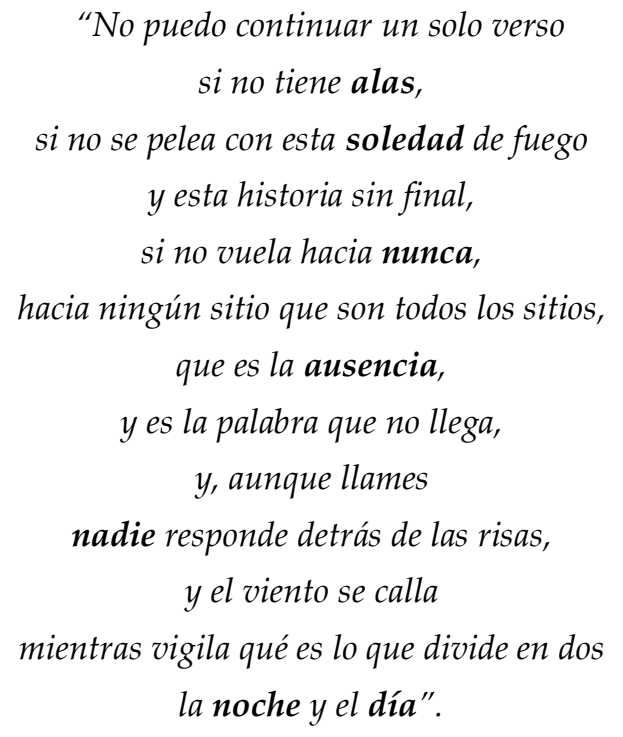

MORATE, ALBERTO, (2019), He llamado hacia nunca, Grupo Terra Trivium, Madrid.

\section{Material y métodos}


La metodología de este análisis, eminentemente cualitativa, incluyó el estudio de cuatro ejemplos de caso: "Estoy vivo", serie de ficción televisiva, en su $3^{\text {a }}$ temporada, producida para TVE, canal generalista, cuyo creador es Daniel Écija, de Globomedia. En su primera temporada consiguió un 14\% share y picos de 2,4 millones de audiencia. Es la apuesta narrativa de la cadena de la noche de los miércoles; "La casa de papel", serie de ficción televisada en la plataforma digital Netflix, en su $3^{\text {a }}$ temporada, cuyo creador es Alex Pina, multipremiada entre otros, con el Emmy Internacional a la Mejor Serie dramática 2018; el largometraje "Yesterday", película de comedia musical dirigida por Danny Boyle en 2019, cuyo guionista es Richard Curtis; y la película revelación del año, "Parasite", film de corte dramático y de misterio, dirigida por Bong Joon-ho, en 2019, también muy galardonada, con la Palma de Oro del Festival de Cannes y Globo de Oro a la mejor película en lengua no inglesa.

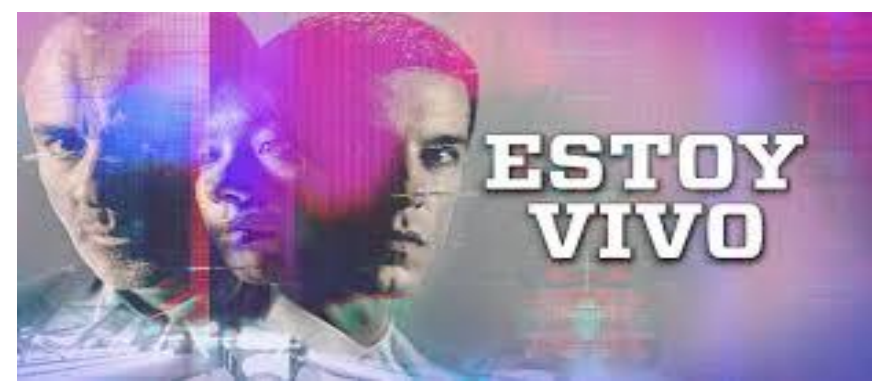

Cartel promocional de TVE

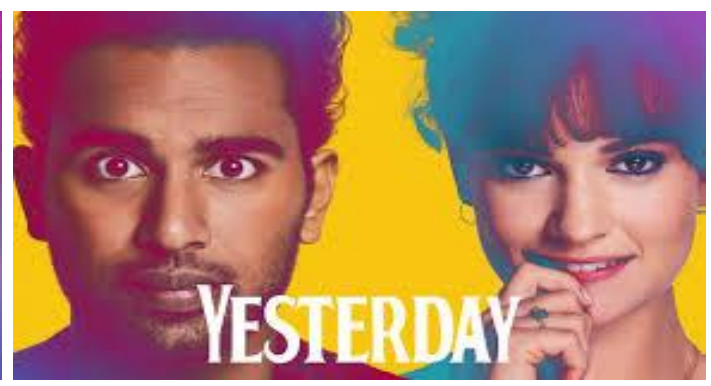

Cartel promocional de la película

La metodología cualitativa estructura un análisis de los cuatro ejemplos de caso para establecer si los nuevos códigos narrativos audiovisuales cuestionan o refrendan, asumen o rechazan, la construcción de una ficción basada en las sustancias expresivas que caracterizan el discurso poético. Una lectura asociada y transversal a este análisis es la "Teoría de la inteligencia creadora":

La actividad creadora transmuta lo trivial en sugerente (...) El proyecto creativo es un tema mendicante habitado por una afectividad que incita a la acción.

MERINA, JOSE ANTONIO, (1993) Teoría de la inteligencia creadora. Tratado de proyectar, Anagrama, Madrid.

Si analizamos la irrupción de la emoción en el discurso audiovisual, otra lectura obligada es el "mundo líquido" de Zygmunt Bauman. Como relatos audiovisuales sujetos a la presión de un seguimiento masivo (audiencias y share, en las series de televisión, número de espectadores y semanas de exhibición, en las películas), este gran sociólogo nos desentraña los nudos entre lo cotidiano y lo único. En nuestro análisis, la dicotomía entre la emoción (individual) y la crítica (pública), entre la intensidad de lo real registrado y la afectividad de la metáfora simbolizada:

Para recuperar su capacidad de excitar, la obra de arte debe ser rescatada de la grisácea cotidianeidad y convertido en un acontecimiento único (...) Para llegar a ser un objeto de deseo, convertirse en una fuente de sensaciones, poder tener, en otras palabras, relevancia para los que viven en la posmoderna sociedad de consumidores, el fenómeno del arte debe manifestarse ahora como acontecimiento.

BAUMAN, ZYGMUNT, (2003) Modernidad líquida, Fondo de Cultura Económica, México. 


\title{
3. Resultados
}

\author{
"Esta mañana me he levantado, \\ Oh, Bella, Ciao, Bella Ciao, Bella Ciao, ciao, ciao, \\ esta mañana me he levantado \\ $y$ he descubierto al invasor. \\ ¡Oh, guerrillero! Quiero ir contigo \\ Oh, Bella Ciao, Bella Ciao, Bella Ciao, ciao, ciao,
}

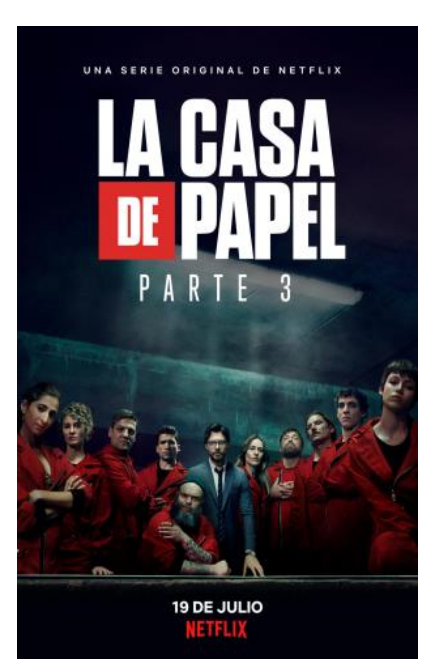

¡Oh, guerrillero, quiero ir contigo porque me siento aquí a morir".

Canción/poema de la resistencia partisana, 1943

La deriva poética de la serie "La Casa de Papel" se inicia con un poema bélico de referencia de las secuencias de acción de la serie, "Bella Ciao", versos conectados a los partisanos italianos que combatían a las potencias del Eje en la Segunda Guerra Mundial y, de nuevo, fue la canción inspiradora para los manifestantes del Mayo 68. "La casa de papel” parte de una doble metáfora: el castillo de naipes y la Casa de la Moneda. Es decir, una metáfora conceptual (el sistema financiero es un engaño) y un oxímoron de libro, una casa sin cimientos, volátil, utópica, vulnerable. Precisamente el eje dramático (y poético) es un ejercicio de síntesis: el desencanto triple de los personajes hacia el sistema, el establishment político y la policía. Nuestros héroes canallas no roban, "fabrican dinero". Sus acciones delictivas son un alarde de resistencia a un sistema del que están excluidos y esta circunstancia social y particular de la juventud en España provoca una identificación automática del espectador en esa horquilla de edad (18-30 años). Es, en definitiva, una oda al anarquismo individualista como respuesta a un sistema político injusto, en el que nada funciona como debería y en que los grupos fácticos, "marionetas en la sombra", ejercen el poder y se apoyan entre sí. Se identificaron indicadores de análisis de uso predominante de la metáfora, de la nobleza y el heroísmo, los personajes son héroes románticos en la de-construcción de un sistema anquilosado e injusto.

La serie de ficción de Televisión Española "Estoy vivo" define muy bien sus ingredientes narrativos: thriller sobrenatural y tragicomedia familiar. Una trama con un ejercicio de autosabotaje permanente, donde los saltos temporales trufados de ciencia ficción psicológica hacen un juego paradójico con un superhéroe de barrio, en este caso, de Vallecas, en Madrid. Esta serie se crea a sí misma, y eso en sí es un paradigma de escritura poética: el protagonista recrea un dilema clásico, un héroe que no puede revelar su identidad y que, a la vez, encarna y busca distintos trajes para la 
misma alma. La reencarnación propia ( y la de las personas que ama, por simpatía) exhibe sustancias expresivas poéticas, como la intensidad y el candor. Intensidad, porque a cada vuelca de tuerca narrativa, con saltos temporales estirados como si fueran chicles, lea acompañan ángeles, terroristas satánicos y enredos policiales. Candor porque, a pesar de las distintas tramas que se niegan entre sí, hay un personaje de la serie, Yago, el enlace, que expresa su ignorancia angelical del mundo terrenal en cada capítulo, al modo de la simbólica película de Wim Wenders, "Cielo sobre Berlín", cuyo guion fue firmado de manera conjunta por el poeta Peter Handke. Lo escribe en un poema el ángel Damiel, interpretado por Bruno Ganz:

$$
\begin{aligned}
& \text { “Cuando el niño era niño, } \\
& \text { no sabía que era niño, } \\
& \text { todo le parecía animado } \\
& \text { y todas las almas eran unas". }
\end{aligned}
$$

WENDERS, WIM, (1987) en la película Cielo sobre Berlín, Argos Films.

Un candor que repite esta serie con nuestro coprotagonista: no sabe de las mezquindades de nuestro mundo, está "fuera de juego" ante las miserias del ser humano actual, ignora la traición, la soberbia y la envidia. Es una mirada emotiva, profunda, esencial. Una mirada poética.

El largometraje "Yesterday" inicia su deriva poética desde su misma trama, en un mundo en que todo es hostil a todo e inarmónico, se cuenta un sueño, un imposible: la simpatía de la subida a los cielos de un impostor, un compositor que plagia los hits de los Beatles sin que nadie, aparentemente, se dé cuenta. El poeta y filósofo Samuel Taylor Coleridge acuñó la expresión "suspensión of disbelief" (suspensión de la incredulidad o fe poética) como la voluntad del espectador/lector de aceptar como ciertas las premisas sobre las cuales se basa una ficción, aunque sean fantásticas o imposibles. En este relato fílmico, lo inverosímil (que todo el Universo "borre" de un plumazo la memoria de las canciones de los Beatles) sucede con un apagón (una suerte de reseteo de las comunicaciones virtuales). Sólo nuestro bribón protagonista escapa de la metáfora y se lucra de ella. No sólo cumple sus sueños, sino que "vive" en ellos. Si, como decía el genial dramaturgo inglés, William Shakespeare, "somos la materia de la que están hechos nuestros sueños", acudamos de nuevo a la voz poética, esta vez de Borges, para indagar qué pasa si nos interrumpen en el proceso onírico:

\footnotetext{
"Si el sueño fuera (como dicen) una

tregua, un puro repaso de la mente, ¿por qué, si te despiertan bruscamente, sientes que te han robado una fortuna?".
}

BORGES, JORGE LUIS, (1964) El sueño, Poemario "El otro, el mismo", Emecé, Buenos Aires. 


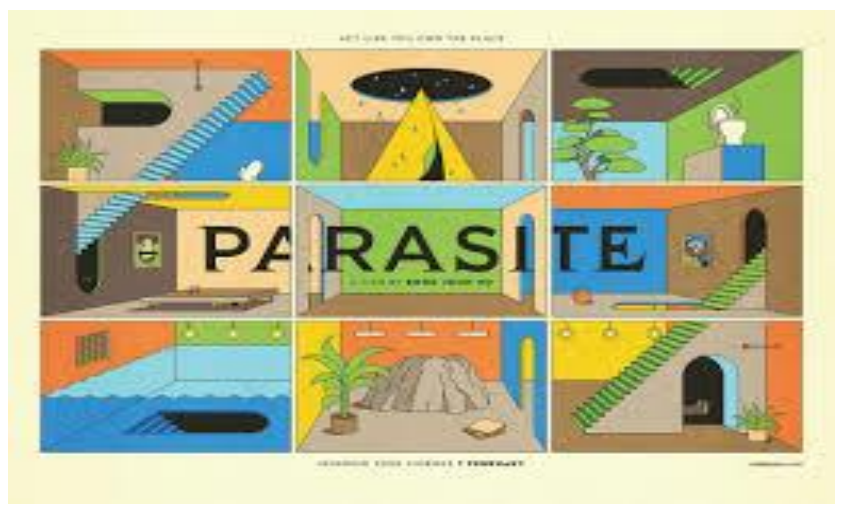

Cartel artístico promocional de la película surcoreana "Parasite".

El último ejemplo de caso es la película revelación del año, "Parasite". Narra la intrahistoria de Corea del Sur, un enigma de espacios sórdidos, personajes con vidas travestidas de embuste y final gore (deudor de Tarantino) y escoge hacerlo ajustándose a las sustancias expresivas de la Poética aristotélica, la purificación del temor y de la compasión. Una dualidad ( muy metafórica, de nuevo) entre el temor de "los otros", coreanos desfavorecidos que viven en las cloacas, sótanos inundados de excrementos y meadas de transeúntes borrachos, frente a la compasión de "los poderosos", mostrados en impolutas viviendas zen de amplias cristaleras y refugios antimisiles nucleares de su vecino del Norte. Carlos F. Heredero, histórico crítico de cine , nos acuña el concepto de "metáfora universal":

"Parasite" se configura cono la metáfora universal: una fábula no realista cuyo terreno de juego es el cine fantástico de sustrato social y político, feroz, salvaje, divertido y revulsivo, estimulante, imprevisible y demoledor".

HEREDERO, CARLOS F. (2019), Cannes 2019 en tiempo real, Caimanediciones.es

$\mathrm{Si}$, como hemos visto, la poesía se nutre de urgencia y necesidad, este relato fílmico juega con ambos conceptos para configurar una arquitectura de poder "jerarquizado", un reflejo de la desigualdad mediante la fotografía de unos espacios "estratificados". Como explica el crítico de cine Juanma Ruiz:

"Bong Joon-ho tiene como espina dorsal la verticalidad: estratifica a sus personajes de arriba abajo, como si fueran su propio montón de cajas de pizza vacías".

RUIZ, JUAN MANUEL (2019) Cannes 2019 en tiempo real, Caimanediciones.es

En el choque de estos dos mundos, esos dos "estratos" (y en el advenimiento de un tercero, el búnker secreto donde correrá la sangre al final de la historia) es donde se produce una febril deriva poética. Este relato constituye la destilación de un guion que, precisamente, ha arrasado a críticos, cineastas y público por la revelación de su tarea narrativa: nombrar la venganza social. En la escritura de este nombre, como decía Susan Sontag, hay un acto poético.

\section{Discusión}


$\mathrm{Si}$, como hemos convenido en el análisis, una de las pruebas fehacientes de la deriva poética en los nuevos códigos de construcción de ficción en el relato audiovisual es el uso de las analogías y las metáforas (en su vertiente poética, no retórica), conviene recordar la máxima teórica de Ricoer y su "metáfora viva"

Hacen falta dos ideas para hacer una metáfora, una dualidad de términos, par de relaciones entre las que actúa la trasposición. (...) La adherencia del sentido a lo sensible.(...) La metáfora describe lo abstracto bajo los rasgos de lo concreto.

RICOER, PAUL (2001) La metáfora viva, Editorial Trotta, Madrid.

En esa dualidad permanente que oscila entre lo sensible/sentido o lo concreto/abstracto, hay voces teóricas que advierten de la existencia de una autoría y un descubrimiento necesarios de las analogías, esa "mirada extrema" (y con otros adjetivos) que reclama el estudio de la experiencia poética.

La anología no funciona por sí sola, se trata de encontrar los actos, los gestos, los procedimientos que, gobernados por el espíritu lúcido, deben captar infaliblemente la realidad absoluta. Aquí el crecimiento sistemático de la conciencia y la sumisión de todos los actos del poeta a una "atención implacable y voraz "son los que tienden a asir la unidad.

BEGUIN, A.(1986) La experiencia poética, Ensayos de crítica literaria, México.

Si los teóricos de la Poética redundan en una "intención creadora" del alma poética, el aporte de los semiólogos y los teóricos de la imagen no se queda atrás: esa "realidad absoluta" que captan los poetas corre en paralelo con el "punctum" de la fotografía, esa realidad inefable que desgarra y atrapa al fotógrafo, al documentalista, al cineasta:

El punctum de una foto es ese azar que en ella me despunta (...) Frente a este "stadium" no soy yo quien va a buscarlo, es él quien sale a escena como una flecha y viene a punzarme: "Punctum" es un pinchazo, agujerito, pequeña mancha, es ese azar que en la fotografía me "despunta", pero también me lastima, me punza.

BARTHES, ROLAND, (1980) La cámara lúcida, Hill \& Wang, Nueva York.

El relato audiovisual y sus nuevos códigos se apropian de la discusión científica sobre el ser poético. Hay autores que insisten en la "conciencia ética" y la responsabilidad compartida, la denuncia del sufrimiento que exige la escritura poética. Parte de esta "nueva moralidad" se reinterpreta y se reescribe en los cuatro ejemplos de caso analizados: la desigualdad social en "La Casa de Papel", el amor trágico, en "Estoy vivo", el artista que plagia en "Yesterday" o la venganza de los desclasados sobre los ricos sin alma de "Parasite". Guionistas y poetas comparten mimbres narrativos:

El poeta es el que guarda la memoria del dolor causado por el hombre, del sufrimiento culpable, para que el ético lo prohíba, para que el moralista evite que eso se repita.

BREZZI, CF F (2006), Introduzione a Ricoer, Editori Laterza, Roma. 
Cuando la nueva ficción audiovisual entra en deriva poética, busca la esencia de las cosas, su relato se vuelve trascendente e intuitivo. De nuevo la literatura científica de los autores que indagan sobre la "necesidad poética" vuelve a aplicarse en este análisis:

Tal es la intuición de los poetas: sólo por la poesía se hace el mundo habitable. Así la poesía se hace esencia histórica $y$, por serlo, es esencia esencial.

BEUCHOT, MAURICIO,(2003) El ser y la poesía: el entrecruce del discurso metafísico y el discurso poético.

Universidad Iberoamericana, México.

Y qué mayor ambición para un relato audiovisual que un registro de la realidad que pueda ofrecer una visión filosófica, metafísica, que explique la fragmentación temporal y espiritual que estamos viviendo en la sociedad actual. En el registro de ese "instante de vida", en la reproducción ficcionada de un avatar cualquiera, en la búsqueda de lo esencial, todos los creadores audiovisuales (no sólo los guionistas, también los realizadores, directores de fotografía, actores y productores) entran en una deriva poética absolutamente necesaria, puesto que es labor de la poesía nombrar. Y estamos huérfanos de categorías:

La poesía es una metafísica instantánea. En un breve poema, debe darse una visión del universo y el secreto de un alma, un ser y unos objetos, todo al mismo tiempo, si sigue simplemente el tiempo de la vida, es menos que la vida, sólo puede ser más que la vida inmovilizando la vida, viviendo en el lugar de los hechos la dialéctica de las dichas y de las penas. Y entonces es principio de una simultaneidad esencial en el que el ser más disperso, en el que el ser más desunido, conquista su unidad.

BACHELARD, GASTÓN, (1932) L 'intuition de l' instant, La Livre de Poche, Paris.

No es extraño que sea un poeta el que cierre este análisis comunicativo. Y lo hace en un trasvase teórico puro, que aquí integramos. Si nuestros relatos audiovisuales son registros (codificados, ficcionados, representados, simbolizados) de nuestro universo real y los poemas se nutren del mismo sustrato para hacer sus analogías, están condenados a entenderse. Poesía visual, por un lado, y narrativa con deriva poética, por otro, que aquí hemos identificado.

El poema es una secuencia en espiral y que regresa sin cesar, sin regresar jamás del todo, a su comienzo. Si la analogía hace del universo un poema, un texto hecho de oposiciones que se resuelven en consonancias, también hacen del poema el doble del Universo.

PAZ, OCTAVIO, (1990) Los hijos del lino, Seix Barral, Barcelona- Bogotá.

\section{Referencias}

Bachelard, Gaston., (1932) L 'intuition de l' instant, La Livre de Poche, Paris.

Barthes, Roland., (1980) La cámara lúcida, Hill \& Wang, Nueva York.

Bauman, Zygmunt., (2003) Modernidad líquida, Fondo de Cultura Económica, México.

Beguin, A.,(1986) La experiencia poética, Ensayos de crítica literaria, México. *

Benedetti, Mario., (1984)_Táctica y estrategia, Poemas de otros, Visor, Madrid. 
Beuchot, Mauricio.,(2003) El ser y la poesía: el entrecruce del discurso metafísico y el discurso poético. Universidad Iberoamericana, México.

Borges, Jorge Luis., (1964) El sueño, Poemario "El otro, el mismo", Emecé, Buenos Aires.

Brezzi, Cf F., (2006), Introduzione a Ricoer, Editori Laterza, Roma.

García García, Francisco., (2019) Presentación poemario "Rimas y Venenos", Icono 14, Madrid.

Levesque, Sara., (2018) Poema al olvido, web Bohemia te adoro, Madrid.

Merina, Jose Antonio., (1993) Teoría de la inteligencia creadora. Tratado de proyectar, Anagrama, Madrid. Morate, Alberto., (2019), He llamado hacia nunca, Grupo Terra Trivium, Madrid.

Paz, Octavio., (1990) Los hijos del lino, Seix Barral, Barcelona- Bogotá.

Ricoer, Paul., (2001) La metáfora viva, Editorial Trotta, Madrid.

Sontag, Susan., (1983) La prosa de un poeta. Cuestión de énfasis. Alfaguara, Madrid.

Valéry, Paul., (2007) Cuadernos (1894-1945), Galaxia Gutemberg, Barcelona.

Wenders, Wim., (1987) en la película Cielo sobre Berlín, Argos Films.

(C) 2020 by the authors. Submitted for possible open access publication under the terms and conditions of the Creative Commons Attribution (CC BY) license (http://creativecommons.org/licenses/by/4.0/). 